\title{
MONITORING HIV EPIDEMIOLOGY USING ASSAYS FOR RECENT INFECTION: WHERE ARE WE?
}

\author{
F Barin ${ }^{1}$, A Nardone (anthony.nardone@hpa.org.uk)² \\ 1. Université François-Rabelais, Inserm ERI 19, Centre National de Référence du VIH, CHU Bretonneau, Tours, France \\ 2. HIV and Sexually Transmitted Infections Department, Health Protection Agency Centre for Infections, London, United Kingdom
}

This issue of Eurosurveillance is dedicated to the widespread advances being made in Europe in the implementation of Serological Testing Algorithms for Recent HIV Seroconversion (STARHS). With the increasing interest in and the use of STARHS to estimate HIV incidence, we believe that the articles regarding the types of assays available [1], the implications for converting laboratory-based data into a real epidemiological measure of incidence [2] and the experiences from France [3], Germany [4] and Portugal [5] of incorporating STARHS methods into national HIV surveillance systems make this issue of Eurosurveillance opportune and of keen interest to a wide readership.

To date, the most important measure to monitor the HIV epidemic has been the reporting of newly diagnosed infections and national surveillance systems are now in place in nearly all European countries [6]. However, the major limitation of this measure is that it does not give an accurate picture of the evolving status of the epidemic as it comprises both people with recent infection and people with infection of several years' duration. In recent years this limitation has been brought into sharp relief in many European countries. Does the increase in many western European countries of diagnosed cases of HIV among men who have sex with men [6] represent a real increase in transmission or a reflection of a greater willingness to test for HIV? In countries such as Portugal, does the shift of newly diagnosed cases of HIV away from injecting drug users and towards those infected by sexual transmission [6] represent the true transmission dynamics of the epidemic? The anticipated benefit of STARHS is to provide answers to these questions by estimating HIV incidence, the number of new infections in a defined time period, and thus enable public health authorities better to target prevention campaigns and resources.

A decade ago, a new strategy based on a testing algorithm that combined two assays, one sensitive and one less sensitive, was proposed to identify a person in the period of early infection, when the antibody titre is increasing but before peak and persistently high antibody response [7]. This strategy requires the use of a commercially available enzyme immunoassay (the sensitive assay) and "detuning" it by increasing dilutions and decreasing incubation times (the less sensitive assay). A blood specimen from a person with early infection is reactive with the commercial assay, but non-reactive with the less sensitive detuned version. The detuned approach has been described using the Abbott HIVAB 3A11 and the BioMérieux Vironostika HIV-1 assay. Unfortunately, both assays were of the early generation immunoassays for HIV antibody screening and, as neither corresponds to the high sensitivity that is demanded, production of both assays has now ceased.

Another approach to identify recent HIV infections is to quantify the avidity of antibodies by modification of third generation antiHIV assays that run on random access analysers [8]. A similar methodology has been successfully applied to diagnose primary infection by rubella virus, cytomegalovirus or toxoplasmosis during pregnancy, in order to provide individual counselling [9]. Although it is not common medical practice, improving the detection of recent infection by combining STARHS results with clinical and laboratory data may have benefit for the patient, by providing an opportunity to discuss enrolment in early intervention studies, and reduce the possibility of onward transmission, by enhancing partner notification procedures [10].

There are a number of important obstacles and threats to the widespread use of STARHS in Europe and globally. The first is to assure the long-term supply of assays. The detuned and avidity STARHS assays require modifications of commercially available assays, and their long-term availability cannot be guaranteed. Alternatively, assays can be developed that are designed specifically for the purpose of identifying recent infection. Such assays can be developed commercially, such as BED-CEIA, or by collaboration between national reference laboratories and public health surveillance institutes, as has been done in France $[3,11]$.

A second obstacle is that a window period must be defined for each assay, and then used for either determination of the frequency of recent infection in a given population or for incidence measurement. In a perfect world, one could imagine that every assay should identify a recent infection based on an identical window period. However, the few comparisons of the existing (past or present) assays clearly showed that there are many discrepancies between assays, particularly because the window period is not similar [12]. This is complicated by the fact that, even when using a single assay, the window period frequently differs when applied to a population different from that used initially for the development, especially in areas where non-B subtypes predominate $[13,14]$, There still remains important work to be done for the validations of the assays and algorithms for estimating incidence from crosssectional blood specimens. 
A third threat is the expertise required to implement the laboratory methods. As outlined in this issue in the article by Murphy and Parry [1], various quality control measures need to be implemented including external quality control procedures. This includes not only assuring and maintaining the operational characteristics of the assay, as outlined in the paragraph above, but also the logistics of rolling out the assay to a wider laboratory network beyond the currently small specialised group of laboratories.

A fourth limitation is the application and integration of STARHS data into routine public health practice. The proportion recently infected is often reported $[10,16]$, but this measure is dependent on HIV testing patterns. The calculation of HIV incidence in the population is much more difficult, as highlighted in this issue by Le $\mathrm{Vu}$ et al [2], and will require significant enhancements and changes to current surveillance systems established to monitor the HIV epidemic. Not only will public health authorities need to obtain improved denominator data, but they will also need to enhance their knowledge of HIV testing patterns in different populations and develop current surveillance datasets to include more laboratory and clinical information with which to validate the results of any tests for recent HIV infection [10].

Although all the assays for recent infections have shown limitations, they have been already used in many circumstances to estimate either HIV incidence or, at least, the proportion of recent infection in various populations. Even if they cannot be recommended for routine use worldwide because of insufficient data on their performance to provide precise incidence in different populations, a few studies have already illustrated their usefulness $[15,16,17]$.

The increasing momentum to incorporate STARHS methodologies within HIV national surveillance systems, particularly with the recent release of American estimates of the national HIV incidence [18], highlight the need for a European strategy to be formulated under the auspices and with the financial support of the European Centre for Disease Control and Prevention. Such a strategy should define the additional studies required not only to ascertain the operational characteristics of the assays but also the epidemiological needs for estimating incidence, thus providing best quality data to health policy makers for the implementation and evaluation of prevention campaigns. It is with the development of such a coordinated strategy that a European voice can provide a vital input into global STARHS initiatives.
5. Cortes Martins H \& Paixão T. Settings for identifying recent HIV infections: The Portugese experience. Eurosurveillance

6. EuroHIV. HIV/AIDS Surveillance in Europe. End-year report 2006. Saint-Maurice: Institut de veille sanitaire, 2007. No. 75.

7. Janssen RS, Satten GA, Stramer SL, Rawal BD, O'Brien TR, Weiblen BJ, et al. New testing strategy to detect early HIV-1 infection for use in incidence estimates and for clinical and prevention purposes. JAMA 1998;280(1):42-8.

8. Suligoi B, Massi F, Galli M, Sciandra M, Di Sora F, Pezzotti P, et al. Identifying recent HIV infections using the avidity index and an automated enzyme immunoassay. JAIDS 2003;32(4):424-8.

9. Andrews JI. Diagnosis of fetal infections. Curr Opin Obstet Gynecol 2004; 16(2):163-166.

10. Fisher M, Pao D, Murphy G, Dean G, McElborough D, Homer G, et al. Serological testing algorithm shows rising HIV incidence in a UK cohort of men who have sex with men: 10 years application. AIDS 2007;21(17):2309-14.

11. Barin F, Meyer L, Lancar R, Deveau C, Gharib M, Laporte A, et al. Development and validation of an immunoassay for identification of recent human immunodeficiency virus type 1 infections and its use on dried serum spots. J Clin Microbiol 2005;43(9):4441-7.

12. Loschen S, Bätzing-Feigenbaum J, Poggensee G, Cordes C, Hintsche B, Rausch M, et al. Comparison of the human immunodeficiency virus (HIV) type 1-specific immunoglobulin $\mathrm{G}$ capture enzyme-linked immunosorbent assay and the avidity index method for identification of recent HIV infections. J Clin Microbiol 2008;46(1):341-5

13. Parekh, B. (2005). Calibration, Validation and Application of the BED Assay for Recent HIV-1 Infection in Multiple Subtypes. Conference on HIV Diagnostics: New Developments and Challenges; 2005 Feb 28-Mar 1: Florida, USA.

14. Sakarovitch C, Rouet F, Murphy G, Minga AK, Alioum A, Dabis F, et al. Do tests devised to detect recent HIV-1 infection provide reliable estimates of incidence in Africa? JAIDS 2007:45(1):115-22.

15. Murphy G, Charlett A, Jordan LF, Osner N, Gill ON, Parry JV, et al. HIV incidence appears constant in men who have sex with men despite widespread use of effective antiretroviral therapy. AIDS 2004;18(2):265-72.

16. Semaille C, Barin F, Cazein F, Pillonel J, Lot F, Brand D, et al. Monitoring the dynamics of the HIV epidemic using assays for recent infection and serotyping among new HIV diagnoses: experience after 2 years in France. J Infect Dis 2007;196(3):377-83.

17. Pillonel J, Barin F, Leperche S, Bernillon P, Le Vu S, Brunet S, et al. Human immunodeficiency virus type 1 incidence among blood donors in France, 1992 through 2006: use of an immunoassay to identify recent infections. Transfusion 2008;48(8):1567-1575.

18. Hall HI, Song R, Rhodes P, Prejean J, An Q, Lee LM et al. Estimation of HIV incidence in the United States. JAMA 2008;300(5):520-9.

This article was published on 4 September 2008.

Citation style for this article: Barin F, Nardone A. Monitoring HIV epidemiology using assays for recent infection: where are we?. Euro Surveill. 2008;13(36): pij=18967. Available online: http://www.eurosurveillance.org/ViewArticle.aspx?ArticleId=18967

\section{References}

1. Murphy G, Parry JV. Assays for the detection of recent infections with human immunodeficiency virus type 1. Euro Surveill. 2008;13(36):pii=18966. Available from: http://www.eurosurveillance.org/ViewArticle.aspx?ArticleId=18966

2. Le Vu S, Pillonel J, Semaille C, Bernillon P, Le Strat Y, Meyer L, Desenclos JC. Principles and uses of HIV incidence estimation from recent infection testing - a review. Euro Surveill. 2008;13(36):pii=18969. Available from: http://www. eurosurveillance.org/ViewArticle.aspx?ArticleId $=18969$

3. Semaille C, Cazein F, Pillonel J, Lot F, Le Vu S, Pinget R, Desenclos JC, Barin F. Four years of surveillance of recent HIV infections at country level, France, mid 2003 - 2006: Experience and perspectives. Euro Surveill. 2008;13(36):pii=18968. Available from: http://www.eurosurveillance.org/ ViewArticle.aspx?ArticleId $=18968$

4. Bätzing-Feigenbaum J, Loschen S, Gohlke-Micknis S, Zimmermann R, Herrmann A, Kamga Wambo O, Kücherer C, Hamouda 0. Country-wide HIV incidence study complementing HIV surveillance in Germany. Euro Surveill. 2008;13(36):pii=18971. Available from: http://www.eurosurveillance.org/ ViewArticle.aspx?ArticleId $=18971$ 